\title{
Correction to: Morel-Lavallée lesions: MRI characteristics in the pediatric patient
}

\author{
Jordan B. Rapp ${ }^{1}$ - Christian A. Barrera ${ }^{1}$ - Victor M. Ho-Fung ${ }^{1,2}$
}

Published online: 12 January 2021

(C) Springer-Verlag GmbH Germany, part of Springer Nature 2021

Correction to: Pediatric Radiology (2019) 49:559-565. https://doi.org/10.1007/s00247-018-4328-0

The authors and editors apologize for the misspelling of Dr. Morel-Lavallée's name throughout this publication. The correct spelling is "Morel-Lavallée."

The corrected title is: Morel-Lavallée lesions: MRI characteristics in the pediatric patient.

The corrected keywords are: Adolescents - Children · Degloving injury $\cdot$ Knee $\cdot$ Morel-Lavallée lesion $\cdot$ Magnetic resonance imaging $\cdot$ Trauma.

Publisher's note Springer Nature remains neutral with regard to jurisdictional claims in published maps and institutional affiliations.

The online version of the original article can be found at https://doi.org/ 10.1007/s00247-018-4328-0

Jordan B. Rapp

rappj@email.chop.edu

1 Department of Radiology, The Children's Hospital of Philadelphia, 3401 Civic Center Boulevard, Philadelphia, PA 19104, USA

2 Perelman School of Medicine, University of Pennsylvania, Philadelphia, PA, USA 